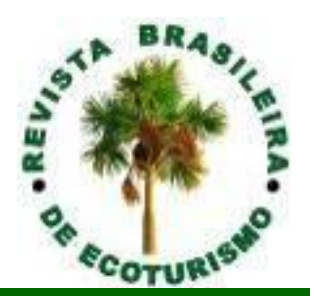

\title{
Quem são e o que pensam os condutores de embarcações turísticas para observação de botos-cinza?
}

\section{Who are and what think the guiana dolphin-watching operators?}

\author{
Josivânia Emanuelly Azevedo dos Santos, Vitor de Oliveira Lunardi, \\ Diana Carvalho de Freitas, Maria Mayara dos Santos Silva, \\ Diana Gonçalves Lunardi
}

RESUMO: Condutores turísticos podem exercer um papel relevante para o desenvolvimento sustentável do ecoturismo, sendo responsáveis pela condução dos turistas durante a visitação, promoção da sensibilização ambiental e cultural e contribuição no monitoramento de impactos socioambientais no local de visitação. Este estudo teve como objetivo descrever quem são e o que pensam os condutores de embarcações turísticas para observação de botos-cinza (Sotalia guianensis). Para tanto, foi registrada a interação entre condutores turísticos e turistas durante 22 passeios de observação de botos-cinza realizados entre 2014 e 2018 na Reserva de Fauna Costeira de Tibau do Sul (REFAUTS), Rio Grande do Norte, Brasil. Adicionalmente, 22 questionários foram aplicados aos condutores de embarcações turísticas na REFAUTS, em maio de 2017 e julho de 2018. Durante os 22 passeios monitorados, os turistas não receberam qualquer informação sobre a REFAUTS ou receberam informação insuficiente sobre a biologia e ecologia de botos-cinza. De acordo com as respostas obtidas nos questionários, condutores turísticos da REFAUTS são predominantemente jovens, com nível de escolaridade fundamental e têm esta atividade como principal fonte de renda. Estes condutores declararam trabalhar na REFAUTS há pelo menos sete anos e ter conhecimento insuficiente sobre a existência desta Reserva. Uma parte significativa destes profissionais também declarou desconhecer a Lei Municipal no 349/2007, que regulamenta o transporte marítimo na REFAUTS. Contudo, estes condutores declararam reconhecer a importância dos seguintes aspectos ambientais para a REFAUTS: boto-cinza, ambiente marinho protegido, normas de conduta, programa de fiscalização e cobrança da taxa turística para a REFAUTS. Os resultados deste estudo poderão subsidiar programas de educação ambiental voltados para os condutores turísticos, tornando-os importantes aliados na conservação de botos-cinza e agentes multiplicadores no processo de sensibilização ambiental de turistas na REFAUTS.

PALAVRAS-CHAVE: Golfinho; Percepção Ambiental; Planejamento Ambiental; Praia de Pipa; Turismo de Observação de Cetáceos. 


\section{ABSTRACT}

Tour operators can play a relevant role in the sustainable development of ecotourism, being responsible for driving tourists during the visitation, promoting environmental and cultural awareness and contributing to the monitoring of social-environmental impacts in the place of visitation. This study aimed to describe who are and what think the Guiana dolphin-watching operators. We recorded the interaction between dolphinwatching operators and tourists during 22 tours conducted between 2014 and 2018 in the Coastal Wildlife Reserve of Tibau do Sul (REFAUTS), Rio Grande do Norte State, Brazil. In addition, 22 questionnaires were applied to dolphin-watching operators at the REFAUTS in May 2017 and July 2018. During the 22 tours monitored, tourists did not receive any information about the REFAUTS or received insufficient information about the biology and ecology of Guiana dophin (Sotalia guianensis). According to the answers obtained in the questionnaires, dolphin-watching operators are predominantly young, with elementary scholarly and have this activity as the main source of income. These dolphin-watching operators reported that they have worked in the REFAUTS for at least seven years and that they have insufficient knowledge about the existence of this Reserve. A significant number of these professionals also reported that they do not know the Municipal Law $n^{\circ} 349 / 2007$, which regulates maritime transport at the REFAUTS. However, these dolphin-watching operators reported that they recognize the importance of the following environmental aspects for the REFAUTS: Guiana dolphin, protected marine area, codes of conduct, inspection program and tourist tax for the REFAUTS. The results of this study may subsidize environmental education programs for dolphin-watching operators, making them important partners in the conservation of Guiana dolphin and multipliers in the process of environmental awareness of tourists in the REFAUTS.

KEYWORDS: Dolphin; Environmental Perception; Environmental Planning; Pipa Beach; Dolphin-Watching.

\section{Introdução}

A relação entre turismo e sustentabilidade é bastante complexa, tendo - ecoturismo um importante potencial na promoção de benefícios socioeconômicos e ambientais (HUNT et al., 2015). Existe uma ampla variedade de definições para o termo 'ecoturismo', o que implica em constantes debates sobre estratégias de gestão que tornem a experiência do visitante mais ambientalmente responsável (ORAMS, 1995). O ecoturismo é um segmento do turismo baseado na natureza, no qual as visitas responsáveis à áreas naturais protegidas contribuem para a conservação da biodiversidade, envolvendo interpretação e educação ambiental dos visitantes e profissionais, além de manter o bem-estar da população local (WOOD, 2002).

Em áreas naturais protegidas, o ecoturismo tem ganhado cada vez mais espaço, por possibilitar o contato do visitante com a natureza, além de valorizar as potencialidades naturais e culturais da região, gerando emprego e renda. Um elemento imprescindível deste processo é o condutor turístico profissional capacitado e cadastrado pelo órgão gestor para: (i) orientar a visitação de forma segura, (ii) promover a sensibilização ambiental e cultural dos visitantes por meio da educação ambiental e (iii) contribuir para o monitoramento de impactos socioambientais no local de visitação (ICMBIO, 
2016). Entretanto, em alguns casos, a interpretação da natureza não é fomentada pelos condutores turísticos, devido à falta de qualificação e conhecimento destes profissionais sobre a área em que atuam (CARVALHO et al., 2015).

Pesquisas sobre percepção ambiental podem subsidiar avaliações e iniciativas de conservação ambiental, pois permitem a compreensão de como os sujeitos, envolvidos no uso dos recursos naturais, adquirem conhecimento e são sensibilizados em relação às questões ambientais (BENNETT, 2016). Ações pró-ambientais de atores sociais envolvidos no ecoturismo em áreas naturais protegidas são influenciadas por múltiplos fatores, como: benefícios econômicos, sensibilização e estrutura governamental (IMRAN et al., 2014).

Estudos sobre a percepção ambiental de atores sociais envolvidos no turismo de observação de cetáceos são fundamentais para subsidiar planos efetivos de conservação de cetáceos e gerenciamento turístico (ARAGONES et al., 2013). Contudo, apesar do elevado número de publicações na literatura científica sobre os turistas de observação de cetáceos (e.g., FINKLER; HIGHAM, 2004; AVILA-FOUCAT et al., 2013; FILBY et al., 2015; BENTZ et al., 2016; SITAR et al., 2017), há pouco esforço científico direcionado aos condutores de embarcação turística, principalmente no que diz respeito à percepção ambiental destes profissionais (e.g., WOODS-BALLARD et al., 2003; SILVA et al., 2014; ZAPETIS et al., 2017).

O turismo de observação de cetáceos, quando desenvolvido sob princípios do ecoturismo, é considerado uma alternativa sustentável, diante da caça comercial de baleias (CHEN, 2011; WEARING et al., 2014). Esse tipo de turismo desempenha um papel de destaque na economia local das comunidades que o realizam (BRENNER et al., 2016) e pode contribuir para a conservação de cetáceos por meio da sensibilização ambiental de turistas (GARCÍA-CEGARRA; PACHECO, 2017). Por outro lado, em virtude de sua crescente popularidade, a introdução de regulamentos específicos para a observação de cetáceos a partir de embarcação tem sido uma importante ferramenta para mitigar os impactos negativos desta atividade e garantir a proteção das espécies-alvo (PARSONS, 2012). Estes regulamentos têm sido tratados por vários autores em diversos países ao redor do mundo, como: Austrália (ver KESSLER; HARCOURT, 2013), Argentina (ver CHALCOBSKY et al., 2017), Escócia (ver PARSONS; WOODS-BALLARD, 2003), Estados Unidos (ver WHITT; READ, 2006), Nova Zelândia (ver GUERRA; DAWSON, 2016), Panamá (ver SITAR et al., 2016), Tonga (ver KESSLER; HARCOURT, 2010) e Brasil (TISCHER et al., 2013).

No Brasil, a regulamentação para a observação de cetáceos foi estabelecida pelo Instituto Brasileiro do Meio Ambiente e dos Recursos Naturais Renováveis - IBAMA, por meio da Portaria nº 117/1996 (alterada pela Portaria no 24/2002), determinando normas que visam à proibição de molestamento intencional de cetáceos em águas jurisdicionais brasileiras (IBAMA, 1996; 2002). Outro instrumento legal para a conservação de cetáceos no país é o Decreto no 6.698/2008, que declara as águas jurisdicionais marinhas brasileiras como santuário de baleias e golfinhos (BRASIL, 2008), reafirmando o interesse nacional na preservação e proteção 
destes animais e permitindo a pesquisa científica e o turismo ordenado. Algumas regiões brasileiras também possuem orientações específicas que estabelecem normas e procedimentos para as embarcações turísticas de observação de cetáceos, a exemplo da Portaria no 5/1995 do IBAMA para observação de golfinho-rotador (Stenella longirostris) no Parque Nacional Marinho de Fernando de Noronha, PE (IBAMA, 1995) e da Portaria no 45/2007 da Fundação Florestal para observação de botos-cinza (Sotalia guianensis) no Parque Estadual llha do Cardoso, SP (FUNDAÇÃO FLORESTAL, 2007).

Na praia de Pipa, município de Tibau do Sul, Rio Grande do Norte, o turismo de observação de botos-cinza ocorre desde 1999 e exerce forte influência na economia local, sendo um dos principais atrativos turísticos da região. Contudo, no início da década passada, alguns estudos realizados na região registraram alterações comportamentais de boto-cinza na presença de embarcações turísticas (ver SANTOS-JR et al., 2006; VALLE; MELO, 2006). Nesse contexto, a Reserva de Fauna Costeira de Tibau do Sul - REFAUTS foi criada por meio do Decreto Municipal no 14, de 17 de fevereiro de 2006, com a finalidade de proteger o boto-cinza e promover o ordenamento turístico na região (TIBAU DO SUL-RN, 2006). No primeiro ano de criação da REFAUTS, a presença das embarcações turísticas parece não ter alterado o padrão comportamental de botos-cinza, considerando naquele ano a recente delimitação desta Reserva e a implantação de normas de controle do turismo de observação de botos-cinza (TOSI; FERREIRA, 2008). Contudo, em anos seguintes, por falta de monitoramento e fiscalização das embarcações turísticas na REFAUTS, outros estudos registraram alterações comportamentais de botos-cinza provocadas por estas embarcações (ver ALBUQUERQUE; SOUTO, 2013; MARTINS et al., 2018). Recentemente, registrou-se a morte de um filhote de boto-cinza causada por uma possível colisão com uma embarcação turística, seguido de comportamento epimelético na enseada dos Golfinhos, zona de uso restrito da REFAUTS (TOLEDO et al., 2017).

A Lei Municipal oㅜ 349 de 28 de dezembro de 2007 regulamenta o transporte marítimo de visitação turística na REFAUTS para o gerenciamento adequado do turismo de observação de botos-cinza (TIBAU DO SUL-RN, 2007). Esta Lei prevê a cobrança de uma taxa turística por cada turista adulto embarcado para o passeio, sendo previsto a aplicação do valor arrecadado pela Prefeitura Municipal de Tibau do Sul no fomento à pesquisa, manutenção e fiscalização da REFAUTS. A proposição desta Lei Municipal no 349/2007 contou com a participação de representantes de quatro setores: (i) poder público, representado pela Prefeitura Municipal de Tibau do Sul, Universidade Federal do Rio Grande Norte, Projeto TAMAR e Instituto de Desenvolvimento Sustentável e Meio Ambiente do Estado do Rio Grande do Norte - IDEMA, (ii) iniciativa privada, (iii) comunidade local e (iv) organizações não governamentais locais. Apesar da promulgação da Lei Municipal no 349/2007, a taxa turística arrecadada diariamente dos turistas embarcados na REFAUTS não tem sido aplicada adequadamente aos fins previstos. Além disso, esta Reserva não conta com plano de manejo e carece de ações efetivas de proteção, monitoramento e fiscalização ambiental. 
Atualmente, a REFAUTS possui 11 embarcações turísticas licenciadas para realização do passeio para observação de botos-cinza (LUNARDI et al., 2017). A Lei Municipal no 349/2007 estabelece as condições adequadas de operação destas embarcações nas zonas de uso restrito e controlado da REFAUTS, como: velocidade máxima de 4 nós; permanência de uma embarcação por vez; motores fora de marcha e proibição de parada para banho a uma distância inferior a 100m do local de observação do boto-cinza, motores desligados quando esta distância for inferior a $50 \mathrm{~m}$ e proibição de eventos de aceleração e perseguição destes animais. Entretanto, na REFAUTS, tem sido frequente o registro de infrações quanto à Lei Municipal no 349/2007, como a presença simultânea de até sete embarcações turísticas na zona de uso restrito da REFAUTS (LUNARDI et al., 2017). Além disso, a prática desordenada do turismo de observação na REFAUTS tem sido associada a alterações comportamentais de botos-cinza (ALBUQUERQUE; SOUTO, 2013; MARTINS et al., 2018).

O boto-cinza é um pequeno cetáceo que ocorre ao longo da costa atlântica da América do Sul e Central, sendo comumente associado à estuários, baías e enseadas (SILVA et al., 2010). Botos-cinza são raramente vistos sozinhos, mas frequentemente observados em pequenos grupos, eventualmente com a presença de filhotes (LUNARDI; FERREIRA, 2014). O boto-cinza é um dos Odontoceti mais vulneráveis ao turismo de observação no Brasil, sendo considerado uma espécie-bandeira, com grande influência para a conservação ambiental de áreas naturais turísticas (SCHLINDWEIN et al., 2011). Este Odontoceti está classificado como 'vulnerável' na Lista de Espécies da Fauna Brasileira Ameaçadas de Extinção (MMA, 2014) e 'com dados insuficientes' na International Union for Conservation of Nature - IUCN (SECCHI, 2012).

Na REFAUTS, os condutores de embarcação turística podem exercer um papel relevante para o desenvolvimento sustentável do ecoturismo, sendo responsáveis pelo cumprimento da Lei Municipal no 349/2007 e pela sensibilização ambiental dos turistas durante o passeio. Dessa forma, compreender quem são e o que pensam estes condutores é imprescindível para o delineamento de estratégias que visem o ordenamento turístico e a promoção de boas práticas de conduta no turismo de observação de botoscinza. Assim, este estudo teve como objetivos: registrar o tipo de interação entre condutores de embarcação turística e turistas durante o passeio para observação de botos-cinza na REFAUTS e descrever o perfil e a percepção destes condutores na REFAUTS.

\section{Material e métodos}

\section{Área de estudo}

A REFAUTS foi criada pelo Decreto Municipal no 14 em 17 de fevereiro de 2006 como uma unidade de conservação da natureza de uso sustentável. Esta Reserva está localizada na praia de Pipa, município de Tibau do Sul, Rio Grande do Norte, Brasil (Figura 1). O clima da região é do tipo tropical chuvoso, com temperatura média anual de $26,4^{\circ} \mathrm{C}$ e precipitação média anual 
de 1530mm (Fonte: INMET, 2017). A área da REFAUTS compreende uma estreita faixa de praia e o ambiente marinho, e é composta por três zonas: zona de uso restrito, zona de uso controlado e zona de amortecimento. A zona de uso restrito da REFAUTS inclui o interior das enseadas dos Golfinhos e do Madeiro - importantes áreas de concentração de botos-cinza (LUNARDI; FERREIRA, 2014).

\section{Coleta de dados}

\section{Interação entre condutores de embarcação turística e turistas}

Os passeios para observação de botos-cinza na REFAUTS incluem visitação à enseada dos Golfinhos, enseada do Madeiro e eventualmente visitação à praia de Cacimbinhas e praia do Amor (Figura 1), com duração total de aproximadamente 50min (LUNARDI et al., 2017). Na REFAUTS, as embarcações turísticas realizam repetidas visitas diárias, que se intensificam em feriados, finais de semana e na alta temporada turística (FREITAS et al., 2016), compreendendo os meses de janeiro, fevereiro, julho e dezembro.

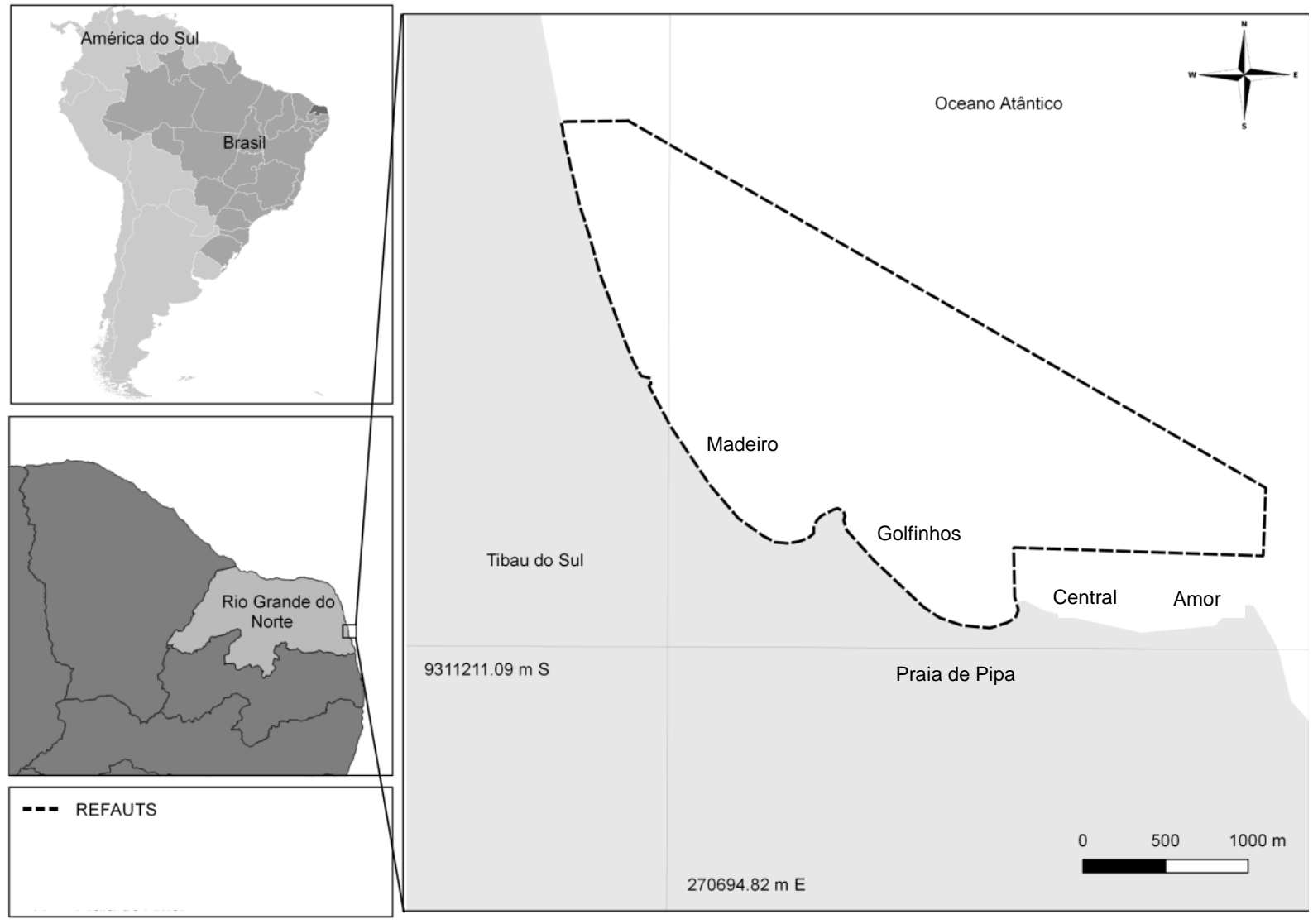

Figura 1: Reserva de Fauna Costeira de Tibau do Sul (REFAUTS), praia de Pipa, município de Tibau do Sul, Rio Grande do Norte, Brasil. Em destaque, a localização geográfica da enseada dos Golfinhos, enseada do Madeiro, praia Central e praia do Amor.

Fonte: Próprios autores.

Figure 1: Coastal Wildlife Reserve of Tibau do Sul (REFAUTS), Pipa beach, Tibau do Sul, Rio Grande do Norte, Brazil. Here highlighted is the geographical location of the Dolphin bay, Madeiro bay, Central beach and Love beach.

Source: Own authors. 
O registro da interação entre condutores de embarcação turística e turistas ocorreu entre os anos de 2014 e 2018 durante 22 passeios para observação de botos-cinza na REFAUTS. Durante estes passeios, três pesquisadores previamente treinados atuaram apenas como observadores, não realizando qualquer tipo de intervenção. Foram registrados: (i) informação transmitida pelo condutor da embarcação antes, durante e imediatamente após o término do passeio, (ii) perguntas realizadas pelos turistas durante 0 passeio e (iii) respostas dos condutores às perguntas dos turistas.

\section{turística \\ Perfil e percepção ambiental dos condutores de embarcação}

Para descrever o perfil dos condutores de embarcação turística e a percepção destes quanto ao turismo de observação de botos-cinza na REFAUTS, três pesquisadores previamente treinados aplicaram questionários à dois condutores de cada uma das 11 embarcações licenciadas da REFAUTS, totalizando 22 questionários. A aplicação dos questionários ocorreu durante quatro dias no mês de maio de 2017 e outros quatro dias no mês de julho de 2018 na praia central de Pipa, local de saída e chegada das embarcações turísticas na REFAUTS, durante o horário de ocorrência dos passeios (09:00h as 16:00h). Os questionários foram aplicados apenas em ocasiões favoráveis à sua realização, ou seja, quando os condutores não estavam no exercício do trabalho.

Todos os condutores de embarcação turística aceitaram participar voluntariamente desta pesquisa, tendo assinado o Termo de Consentimento Livre e Esclarecido (TCLE), que continha: apresentação e contato do grupo de pesquisadores, objetivo da pesquisa, importância da participação, sigilo da identidade do condutor e indicação do uso dos resultados da pesquisa exclusivamente para fins científicos, seguindo orientações da Resolução de $n^{\circ}$ 510/2016 do Conselho Nacional de Saúde (CNS), que trata das normas para pesquisas em Ciências Humanas e Sociais (BRASIL, 2016). Este estudo é parte integrante do projeto de pesquisa intitulado 'Turismo de observação de golfinhos na praia de Pipa, $\mathrm{RN}$ ' aprovado pelo comitê de ética para pesquisas em Ciências Humanas e Sociais sob o número CAAE: 45761315.6.0000.5294.

As temáticas abordadas no questionário destinado aos condutores de embarcação turística na REFAUTS foram:

- perfil do condutor: idade, escolaridade e função. Há quanto tempo você é um operador turístico? A atividade turística de observação de botos-cinza é a sua única fonte de renda?

- REFAUTS: Você sabe o que é a REFAUTS? Você participa das reuniões do conselho gestor desta Reserva?

- turismo de observação de botos-cinza: Você participa de alguma associação ou cooperativa de turismo de observação de botos-cinza? Você recebeu treinamento para operar as embarcações de turismo de 
observação de botos-cinza? A Prefeitura de Tibau do Sul tem normas para observação de botos-cinza a partir de embarcação? Durante a observação de botos-cinza, o quão perto você acredita que a embarcação chega destes golfinhos $(<5 \mathrm{~m}, 5-10 \mathrm{~m}, 11-30 \mathrm{~m}, 31-50 \mathrm{~m}, 51-$ $100 \mathrm{~m},>100 \mathrm{~m})$ ? Você acredita que a taxa turística cobrada pela Prefeitura de Tibau do Sul por cada turista embarcado está sendo destinada para melhorias na gestão da REFAUTS? e

- grau de importância, utilizando uma escala qualitativa com cinco categorias - não importante, pouco importante, importante, muito importante e extremamente importante - Para você, qual o grau de importância dos seguintes elementos: boto-cinza, ambiente marinho protegido, normas de conduta, programa de fiscalização e cobrança de uma taxa turística para a REFAUTS?

\section{Análise de dados}

Os dados referentes à interação entre condutores de embarcação turística e turistas foram analisados de acordo com a abordagem qualitativa, que busca significado na fala do sujeito, estando interligado ao contexto em que eles estão inseridos (ALVES; SILVA, 1992). Para melhor descrição e interpretação dos dados sobre perfil e percepção ambiental dos condutores de embarcação turística e grau de importância dos componentes do turismo de observação de botos-cinza, foi utilizada a análise estatística descritiva.

\section{Resultados e discussão}

\section{Interação entre condutores de embarcação turística e turistas}

$\mathrm{Na}$ REFAUTS, não há registro de ocorrência de palestras direcionadas aos turistas antes ou durante o passeio para observação de botos-cinza, de acordo com informações obtidas junto à Prefeitura Municipal de Tibau do Sul. Adicionalmente, de 2014 a 2018, durante a coleta de dados na REFAUTS, nenhum dos pesquisadores deste estudo registrou qualquer tipo de palestra direcionada aos turistas. Contudo, durante os passeios para observação de botos-cinza, os condutores de embarcação turística forneceram aos turistas informações sobre a história da praia de Pipa e a localização das enseadas dos Golfinhos e do Madeiro, da praia do Amor, do Santuário Ecológico de Pipa e do Projeto TAMAR. Antes ou durante esses passeios, os condutores turísticos não divulgaram quaisquer informações sobre a REFAUTS ou sobre a biologia e o status de conservação de botos-cinza. Entretanto, quando questionados, condutores de embarcação turística forneceram as seguintes informações aos turistas: distribuição e taxa de ocorrência de botos-cinza na REFAUTS, hábitos de alimentação de botos-cinza, presença de filhotes e profundidade das enseadas dos Golfinhos e do Madeiro (Quadro 1). 
Quadro 1: Perguntas e respostas mais frequentes registradas nas interações entre condutores de embarcação turística e turistas durante o passeio para observação de botoscinza (Sotalia guianensis) na Reserva de Fauna Costeira de Tibau do Sul (REFAUTS), praia de Pipa, município de Tibau do Sul, Rio Grande do Norte, Brasil.

Table 1: Questions and answers recorded frequently during interactions between dolphinwatching operators and tourists during tours in the Coastal Wildlife Reserve of Tibau do Sul

(REFAUTS), Pipa beach, Tibau do Sul municipality, Rio Grande do Norte, Brazil.

\begin{tabular}{|l|l|}
\hline Perguntas realizadas pelos turistas & $\begin{array}{l}\text { Respostas fornecidas pelos condutores de } \\
\text { embarcação turística }\end{array}$ \\
\hline $\begin{array}{l}\text { Qual a profundidade do local de banho nas } \\
\text { enseadas dos Golfinhos e do Madeiro? }\end{array}$ & 3 a $4 \mathrm{~m}$ de profundidade. \\
\hline Existe tubarão aqui nas enseadas? & Não. \\
\hline Há botos-cinza todos os dias nas enseadas? & Sim. \\
\hline $\begin{array}{l}\text { Onde os botos-cinza estão quando não os } \\
\text { encontramos aqui nas enseadas? }\end{array}$ & $\begin{array}{l}\text { No alto mar ou em outras áreas litorâneas da } \\
\text { região como lagoa de Guaraíras, praia do Amor e } \\
\text { Baía Formosa. }\end{array}$ \\
\hline $\begin{array}{l}\text { Existem filhotes de botos-cinza aqui nas } \\
\text { enseadas? }\end{array}$ & Sim, inclusive há um filhote albino. \\
\hline Podemos alimentar os botos-cinza? & $\begin{array}{l}\text { É proibido qualquer contato direto com os botos- } \\
\text { cinza, incluindo alimentá-los ou tocá-los. }\end{array}$ \\
\hline $\begin{array}{l}\text { Quais os peixes que os botos-cinza se } \\
\text { alimentam? }\end{array}$ & Principalmente tainha. \\
\hline
\end{tabular}

Fonte: Próprios autores. Source: Own authors.

No turismo de observação de cetáceos, o fornecimento de informações sobre as espécies-alvo e o ambiente marinho é uma importante fonte de sensibilização ambiental para os turistas (GARCÍA-CEGARRA; PACHECO, 2017). A introdução de programas de educação e interpretação ambiental é uma estratégia desse turismo para alcançar práticas sustentáveis (ANDERSEN; MILLER, 2006). Em geral, estes programas fornecem informações sobre a conservação da vida marinha e gerenciam com cautela as interações entre embarcações e cetáceos (ZEPPEL; MULOIN, 2014). Entretanto, passeios sem diálogos educacionais a bordo, onde os condutores turísticos não têm conhecimento ou treinamento específico, não promovem a sensibilização ambiental de turistas (PONNAMPALAM, 2011). Vale destacar que os turistas preferem aqueles passeios em que o condutor de embarcação turística apresenta práticas adequadas de conduta e fornece um componente educacional (LÜCK, 2015; BENTZ et al., 2016; SITAR et al., 2017). Desta forma, a implantação de um programa contínuo de interpretação e educação ambiental que envolva condutor de embarcação turística e turistas é fundamental para o gerenciamento do turismo de observação de botos-cinza na REFAUTS.

\section{Perfil e percepção ambiental dos condutores de embarcação turística}

Os 22 condutores de embarcação turística que atuam na REFAUTS e que participaram deste estudo são do sexo masculino e declararam ter entre 23 e 59 anos, com idade média $( \pm$ DP) de $36 \pm 9$ anos. Metade dos 
participantes declarou ter entre 31 e 45 anos $(n=11)$, enquanto $36,4 \%(n=8)$ declarou ter entre 18 e 30 anos. Apenas $13,4 \%$ dos condutores $(n=3)$ declararam ter idade superior a 46 anos, o que ressalta que os condutores de embarcação turística na REFAUTS constituem-se, majoritariamente, em um grupo de jovens profissionais. Resultado semelhante foi descrito por Pereira et al. (2015), onde os condutores de embarcação turística do Parque Nacional Marinho de Fernando de Noronha, eram, em sua maioria, do sexo masculino e possuíam idade entre 19 e 35 anos.

Ao investigar o grau de instrução dos condutores de embarcação turística, mais de metade destes $(59,1 \%, \mathrm{n}=11)$ declarou ter nível de escolaridade fundamental, enquanto $27,3 \%(n=6)$ declararam ter nível médio. Somente $13,6 \%(n=3)$ declararam não ser alfabetizados. Nenhum condutor de embarcação turística declarou ter nível de escolaridade superior. $\mathrm{O}$ fato da maioria destes condutores terem permanecido no ambiente escolar por menos de 12 anos indica a necessidade de uma formação complementar que vise desenvolver habilidades, especialmente na área de conservação dos recursos naturais, desenvolvimento sustentável e ecoturismo. Silva et al. (2014), por meio da caracterização da atividade de observação de botos-cinza no Rio Grande do Norte, também registrou baixa escolaridade dos condutores de embarcação turística na praia de Pipa e em Baía Formosa. Por outro lado, - Parque Nacional Marinho de Fernando de Noronha parece experimentar uma realidade mais adequada, no qual a maioria dos condutores turísticos possuem nível de escolaridade médio (PEREIRA et al., 2015), o que pode contribuir para o desenvolvimento adequado de um programa de educação ambiental voltado para estes profissionais.

A REFAUTS foi criada em 2006 por meio do Decreto Municipal o 14. Apesar disso, apenas metade dos condutores de embarcação turística (11 condutores) que participaram deste estudo declararam saber da existência da REFAUTS. Destes, 36,4\% declararam que já participaram de reuniões do conselho gestor desta Reserva. O fato de 11 condutores de embarcação turística declararem desconhecimento sobre a REFAUTS é preocupante, pois esta Reserva foi criada com o principal objetivo de conservação de botoscinza e tartarugas marinhas. Além disso, a REFAUTS conta com a Lei Municipal no 349/2007 que regulamenta o transporte marítimo nesta Reserva, de forma a minimizar os danos causados pelas embarcações turísticas aos botos-cinza. Se uma parte significativa dos condutores turísticos declararam desconhecer a REFAUTS, como esperar que estes mesmos condutores cumpram normas de conduta das embarcações, respeitando a fauna marinha local? Ainda, como esperar que estes condutores orientem os turistas embarcados durante o seu passeio na REFAUTS, se eles mesmos declararam desconhecer a existência desta Reserva?

Durante a realização deste estudo, três condutores de embarcação turística destacaram a necessidade de um treinamento ambiental específico voltado para sua categoria e cobraram a implantação de programas educacionais pelo Poder Público na REFAUTS. Os condutores turísticos possuem um relevante papel no desenvolvimento do ecoturismo em áreas naturais (RIBAS; HICKENBICK, 2012). Adicionalmente, os programas de educação e interpretação que promovem a sensibilização ambiental são 
benéficos para alcançar a sustentabilidade do turismo de observação de cetáceos (JOHNSON; MCLNNIS, 2014). Em Taiwan, por exemplo, 33\% dos condutores turísticos relataram observar iniciativas sustentáveis de outros condutores durante a observação de cetáceos, após implantação de um programa ecoturístico do governo local voltado para esta categoria (CHEN et al., 2011). Treinamentos ambientais contribuem para conscientização e reflexão destes profissionais, ressaltando a importância de sua função para garantir o desenvolvimento ecoturístico (WALKER; WEILER, 2016). Portanto, na REFAUTS é imprescindível à execução de um programa contínuo de treinamento e capacitação ambiental para os condutores turísticos, visando a ampliação de conhecimento sobre a REFAUTS e sobre a proteção do botocinza, espécie atualmente ameaçada de extinção e alvo constante do ecoturismo.

O turismo de observação de botos-cinza parece ser a única fonte de renda da maioria dos condutores turísticos $(81,8 \%, n=18)$, segundo suas declarações. $\mathrm{Na}$ REFAUTS, apenas $18,2 \%$ dos condutores turísticos declararam exercer outra atividade - a pesca, por exemplo - como principal fonte de renda. Silva et al. (2014) também constatou esta atividade como a principal fonte de renda de condutores turísticos no litoral sul do Rio Grande do Norte. Quando questionados sobre seu tempo como condutor de embarcação turística na REFAUTS, a maioria destes profissionais declarou trabalhar nesta função há pelo menos sete anos. Na Escócia, a maioria dos condutores de embarcação turística declarou trabalhar há mais de 10 anos na atividade de observação de cetáceos (WOODS-BALLARD et al., 2003; RYAN et al., 2018). Os resultados apresentados neste estudo evidenciam a necessidade de integrar os condutores de embarcação turística, e sua ampla experiência profissional, aos programas de educação e sensibilização ambiental, tornando-os importantes promotores de conservação de botoscinza na REFAUTS.

A observação de botos-cinza a partir de embarcação ocorre há aproximadamente duas décadas na REFAUTS. Contudo, uma parte significativa dos condutores de embarcação turística que fizeram parte deste estudo $(95,5 \%, n=21)$ declarou não participar de nenhum tipo de associação ou cooperativa no ramo do turismo. Apenas um condutor declarou participar de uma associação de comerciantes de tíquete para o passeio de observação de botos-cinza. A associação de condutores turísticos constitui-se em instrumento participativo fundamental para a sustentabilidade e manutenção da atividade, promovendo a capacitação destes profissionais, por meio de cursos de treinamento e qualificação, além de permitir o monitoramento de informações relevantes como número de turistas e de embarcações, pesca e comportamento e abundância de cetáceos (ARAGONES et al., 2013). Dessa forma, a criação de uma associação de condutores turísticos da REFAUTS poderá contribuir para a gestão adequada do ecoturismo e para a formação continuada de seus associados, promovendo inclusive a conservação de botos-cinza nesta Reserva.

O treinamento contínuo de condutores para operação de embarcação turística pode resultar em práticas adequadas de visitação ecoturística. $\mathrm{Na}$ REFAUTS, segundo declaração da maioria dos condutores de embarcação 
turística $(72,7 \%, n=16)$, o treinamento para operação de embarcações foi fornecido pela Marinha do Brasil ou pelos próprios proprietários destas embarcações. A Prefeitura Municipal de Tibau do Sul, responsável pela gestão da REFAUTS, não foi mencionada por nenhum destes condutores. Dessa forma, é possível que a Prefeitura Municipal de Tibau do Sul não esteja contribuindo, de forma adequada, com sua responsabilidade de gestão da REFAUTS, prevista na Lei Municipal $n^{\circ} 349 / 2007$, tendo em vista a ausência de cursos de formação e programas de monitoramento e fiscalização ambiental. $O$ contato limitado entre gestores de recursos naturais e condutores turísticos é um desafio para o ecoturismo, pois compromete o desenvolvimento sustentável dessa indústria diante da falta de diálogo entre as partes interessadas (DIMMONICK et al., 2014). Cabe destacar que a ausência de ações efetivas, que deveriam ser promovidas por políticas públicas no turismo, pode comprometer, não só a atividade ecoturística, como também a preservação dos recursos naturais (MORAES, 2015).

A observação de botos-cinza na REFAUTS a partir de embarcação é regulamentada pela Lei Municipal $n=349$, publicada em 2007. De acordo com esta Lei, o motor da embarcação deve permanecer fora de marcha, quando a embarcação estiver em distância inferior a 100m dos botos-cinza, e desligado, em distância inferior a 50m. Em 2017 e 2018, quando os questionários foram aplicados aos condutores de embarcação turística na REFAUTS, apenas $54,5 \%(n=12)$ afirmaram ter conhecimento da existência dessa Lei. Além disso, grande parte dos condutores declarou que sua embarcação comumente se mantém muito próxima do boto-cinza: $45,5 \%(n=10)$ declararam aproximar-se entre $11-30 m ; 40,9 \%(n=9)$, entre $5-10 m ; 9,1 \%(n=$ $2)$, entre $31-50 \mathrm{~m}$ e $4,5 \%(n=1)$, declararam aproximar-se a distâncias inferiores a $5 \mathrm{~m}$. Logo, deduz-se que a Lei que regulamenta o transporte marítimo na REFAUTS ainda é pouco conhecida e não têm sido cumprida pelos condutores de embarcação turística. A falta de conformidade do turismo de observação de botos-cinza com a legislação vigente já foi inclusive descrita anteriormente (ver LUNARDI et al., 2017). O transporte marítimo na REFAUTS parece apresentar baixo nível de conformidade com a legislação vigente, o que pode resultar em uma ameaça para o boto-cinza. Diante deste cenário, torna-se necessário a implantação de medidas de gestão ambiental que fomentem, o quanto antes, a conformidade do turismo de observação de botos-cinza na REFAUTS.

Diante de uma gestão adequada da indústria do ecoturismo, condutores turísticos cumprem códigos voluntários ou regulamentos governamentais para observação de cetáceos (ver PARSONS; WOODSBALLARD, 2003; TISCHER et al., 2013; GUERRA; DAWSON, 2016). Por outro lado, é comum na literatura científica registros de descumprimento dos regulamentos vigentes pelos condutores turísticos, diante do crescimento desordenado e gestão inadequada do turismo de observação de cetáceos (ver WHITT; READ, 2006; HOWES et al., 2012; KESSLER; HARCOURT, 2013; FILBY et al., 2015; SITAR et al., 2016; RYAN et al., 2018). Os regulamentos para o turismo de observação de cetáceos são criados principalmente para evitar perturbações às espécies-alvo. No entanto, estas espécies também podem constituir-se em uma importante ferramenta de 
marketing para os condutores turísticos (WOODS-BALLARD et al., 2003), pois aumentam a probabilidade de retorno dos turistas às áreas visitadas (AVILA-FOUCAT et al., 2013). Além disso, a proximidade entre a embarcação e os cetáceos parece não exercer forte influência na satisfação dos turistas (ORAMS, 2000). Em geral, uma parte significativa dos turistas se preocupa com potenciais efeitos adversos associados à observação de cetáceos (FINKLER; HIGHAM, 2004), podendo inclusive contribuir para o aumento da conformidade do condutor turístico durante o passeio, ao exigir práticas sustentáveis da atividade (FILBY et al., 2015).

De acordo com o Art. 9 da Lei Municipal no 349/2007, o valor arrecadado com a taxa turística para observação de botos-cinza deve ser aplicado em ações de pesquisa, manutenção e fiscalização na REFAUTS. Quando questionados sobre a existência desta taxa, a maioria dos condutores $(86,4 \%, n=19)$ acredita que o valor arrecadado pela Prefeitura Municipal de Tibau do Sul não está sendo destinado à tais melhorias na gestão da REFAUTS. Vale destacar que esta taxa turística vem sendo cobrada desde 2008 e a estimativa da receita obtida com o turismo de observação de botoscinza na REFAUTS pode ser considerada suficiente para a implantação de ações de educação, monitoramento e fiscalização ambiental desta Reserva (LUNARDI et al., 2017).

Neste estudo, a percepção dos condutores de embarcação turística foi avaliada de acordo com o grau de importância de: (i) boto-cinza (ii) ambiente marinho protegido, (iii) normas de conduta, (iv) fiscalização e (v) cobrança da taxa turística prevista na Lei Municipal no 349/2007. Estes condutores apontaram, em $45,5 \%$ dos casos $(n=10)$, o boto-cinza como 'extremamente importante' para a REFAUTS (Figura 2a). Adicionalmente, apontaram como 'muito importante' a proteção do ambiente marinho (Figura 2b) e como 'importante' a existência de normas de conduta para o ordenamento do turismo de observação de botos-cinza (Figura 2c), a fiscalização das atividades turísticas na REFAUTS (Figura 2d) e a cobrança da taxa turística prevista na Lei Municipal no 349/2007 (Figura 2e). Vale salientar que nenhum condutor de embarcação turística declarou que os aspectos investigados sobre a REFAUTS são 'não importantes' ou 'pouco importantes'.

O reconhecimento da importância do boto-cinza pelos condutores de embarcação turística também foi relatado por Silva et al. (2014) na área de estudo, onde os profissionais reconheceram a conservação deste cetáceo como necessário à manutenção do turismo. A inclusão de profissionais cientes da importância da conservação da natureza em práticas ecoturísticas permite que o objetivo de preservação seja alcançado (ALVES et al., 2016). Entretanto, vale ressaltar que declarações pró-conservacionistas dos condutores turísticos em relação aos cetáceos nem sempre resultam em adesão à práticas sustentáveis na observação destes animais (ZAPETIS et al., 2017), tornando-se necessário a implantação de um programa contínuo de educação ambiental voltado aos condutores turísticos, e de um programa de monitoramento e fiscalização do turismo de observação de botos-cinza na REFAUTS. 

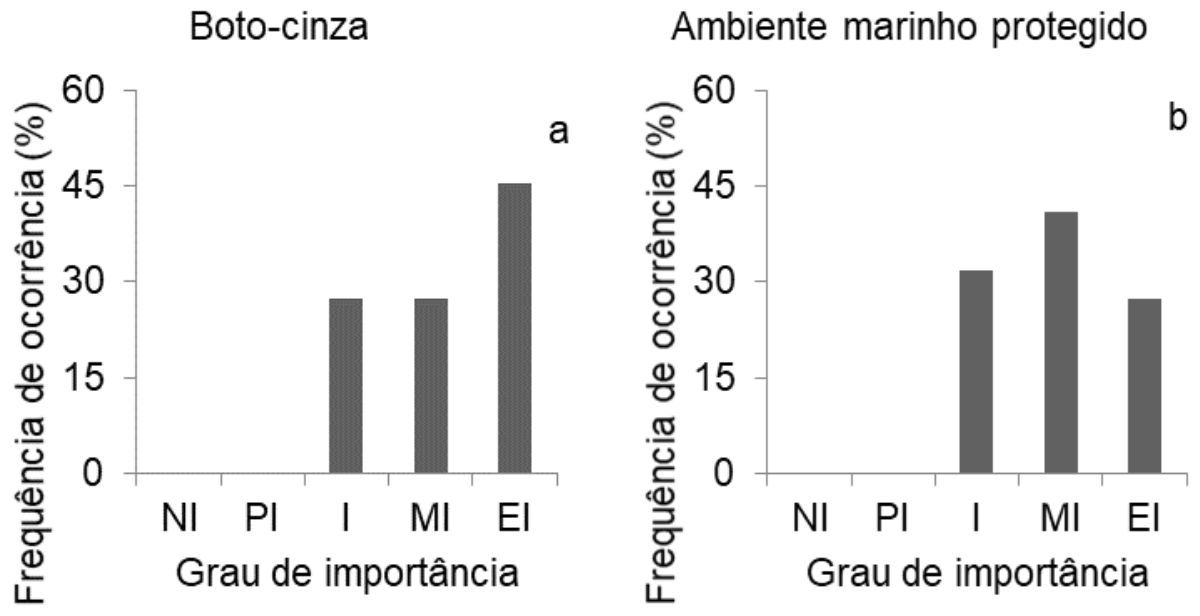

Normas de conduta
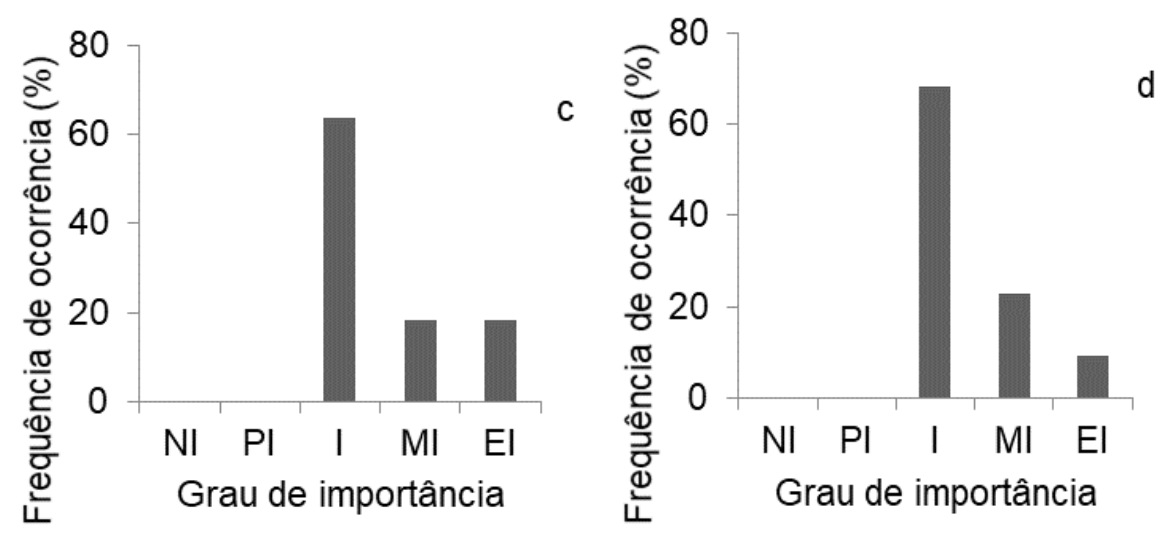

Cobrança da taxa turística

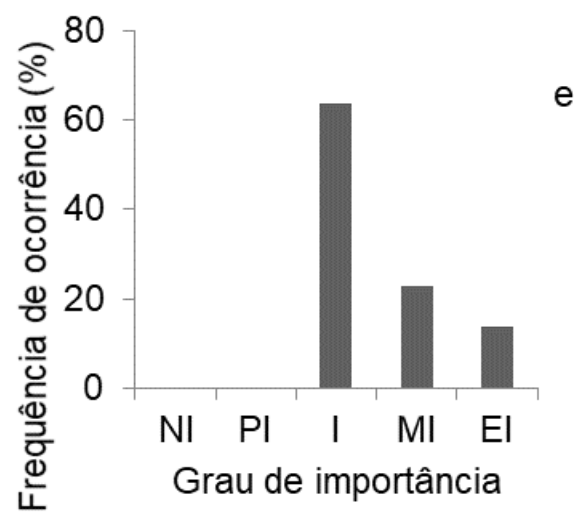

Figura 2: Grau de importância de cinco aspectos associados à Reserva de Fauna Costeira de Tibau do Sul (REFAUTS) para os condutores do turismo de observação de botos-cinza (Sotalia guianensis): (a) boto-cinza, (b) ambiente marinho protegido, (c) fiscalização, (d) normas de conduta e (e) cobrança da taxa turística. NI: Não é importante. PI: Pouco importante. I: Importante. MI: Muito importante. El: Extremamente importante. Fonte: Próprios autores.

Figure 2: Degree of importance of five aspects associated with the Coastal Wildlife Reserve of Tibau do Sul (REFAUTS) according to the dolphin-watching operators: (a) Guiana dolphin, (b) protected marine area (c) inspection, (d) codes of conduct (e) tourist tax. NI: It's not important. PI: Little important. I: Important. MI: Very important. El: Extremely important.

Source: Own authors. 


\section{Considerações finais}

Apesar da relevância ambiental e socioeconômica da REFAUTS e da existência da Lei Municipal no 349/2007 para a regulamentação das atividades do turismo de observação de botos-cinza, ainda não são ministradas palestras de sensibilização ambiental para os turistas e os condutores de embarcação turística declararam ter pouco conhecimento sobre os aspectos ambientais desta Reserva. Diante dos resultados apresentados neste estudo, recomenda-se: (i) um programa de educação e interpretação ambiental para os turistas de observação de botos-cinza; (ii) a criação de uma associação de condutores turísticos que participe ativamente do conselho gestor da REFAUTS, de forma a contribuir para a gestão adequada desta Reserva; (iii) um programa de educação ambiental continuada voltado para os condutores turísticos, que poderá promover o conhecimento sobre a Lei Municipal no 349/2007, além dos aspectos de ecologia e biologia do boto-cinza e a importância de uma gestão adequada da REFAUTS para a sustentabilidade do ecoturismo em longo prazo; (iv) um programa contínuo de monitoramento e fiscalização das atividades turísticas na REFAUTS e (v) a destinação de parte do valor arrecadado com a taxa turística para subsidiar programas educacionais e programas de monitoramento e fiscalização das atividades turísticas na REFAUTS.

Vale ressaltar que, apesar do baixo nível de conformidade do transporte marítimo na REFAUTS, os condutores de embarcação turística reconhecem a importância dos aspectos ambientais e de controle envolvidos no turismo de observação de botos-cinza na REFAUTS e destacam a necessidade de um treinamento ambiental específico para a categoria. Dessa forma, por meio do programa de educação ambiental continuada, espera-se que estes condutores se tornem importantes aliados na conservação de botos-cinza. Os resultados apresentados neste estudo devem subsidiar ações que fomentem a sustentabilidade do turismo de observação de botos-cinza em longo prazo.

\section{Referências}

ALBUQUERQUE, N.S.; SOUTO, A.S. Motorboat noise can potentially mask the whistle sound of estuarine dolphins (Sotalia guianensis). Ethnobiology and Conservation, v. 2, 2013. Disponível em: http://ethnobioconservation. com/index.php/ebc/article/view/26/97. Acesso em: 22 set. 2017.

ALVES, M.S.; DE-BORTOLI, A.L.; KIRST, F.V.; MESSIAS, S.M.; DE-BORTOLIR. Normalização do ecoturismo e turismo de aventura no Brasil. Revista Brasileira de Ecoturismo, v. 9, n. 3, p. 433-444, 2016.

ALVES, Z.M.M.B.; SILVA, M.H.G.F. Análise qualitativa de dados de entrevista: uma proposta. Paidéia (Ribeirão Preto), n. 2, p. 61-69, 1992.

ANDERSEN, M.S.; MILLER, M.L. Onboard marine environmental education: Whale watching in the San Juan Islands, Washington. Tourism in Marine Environments, v. 2, n. 2, p. 111-118, 2006. 
ARAGONES, L.V.; TALAUE-MCMANUS, L.; ROQUE-BORIGAS, M.A.A.; AMOR, A.K.S.; KEITH, E.O. Dolphin watching in the southern Tanon Strait protected seascape, Philippines: issues and challenges. Science Diliman, v. 25, n. 2, p. 133, 2013.

AVILA-FOUCAT, V.S.; VARGAS, A.S.; JORDAN, A.F.; FLORES, O.M.R. The impact of vessel crowding on the probability of tourists returning to whale watching in Banderas Bay, Mexico. Ocean \& Coastal Management, v. 78, p. 1217, 2013.

BENNETT, N.J. Using perceptions as evidence to improve conservation and environmental management. Conservation Biology, v. 30, n. 3, p. 582-592, 2016.

BENTZ, J.; LOPES, F.; CALADO, H.; DEARDEN, P. Enhancing satisfaction and sustainable management: Whale watching in the Azores. Tourism Management, v. 54, p. 465-476, 2016.

BRASIL. Decreto № 6.698, de 17 de dezembro de 2008. Declara as águas jurisdicionais marinhas brasileiras Santuário de Baleias e Golfinhos do Brasil. Diário Oficial da União, Poder Executivo, Brasília, DF, 17 dez. 2008. Seção 1, n. 246, p. 6.

BRASIL. Resolução de $n^{\circ}$ 510, de 07 de abril de 2016. Trata das especificidades éticas das pesquisas nas ciências humanas e sociais e de outras que utilizam metodologias próprias dessas áreas. Diário Oficial da União, Poder Executivo, Brasília, DF, 24 mai. 2016. Seção, n. 98, p. 44-46.

BRENNER, L.; MAYER, M.; STADLER, C. The economic benefits of whale watching in El Vizcaíno Biosphere Reserve, Mexico. Economía, Sociedad y Territorio, v. 16, n. 51, p. 429-457, 2016.

CARVALHO, V.C.; CAMARGO, F.F.; FONTES, M.A.L. A interpretação da natureza e sua aplicação por agentes do ecoturismo no Mato Grosso. Revista Brasileira de Ecoturismo, v. 8, n. 5, p. 708-716, 2015.

CHALCOBSKY, B.A.; CRESPO, E.A.; COSCARELLA, M.A. Whale-watching in Patagonia: What regulation scheme should be implemented when the socioecological system is changing? Marine Policy, v. 75, p. 165-173, 2017.

CHEN, C. From catching to watching: Moving towards quality assurance of whale/dolphin watching tourism in Taiwan. Marine Policy, v. 35, n. 1, p. 10-17, 2011.

DIMMOCK, K.; HAWKINS, E.R.; TIYCE, M. Stakeholders, industry knowledge and adaptive management in the Australian whale-watching industry. Journal of Sustainable Tourism, v. 22, n. 7, p. 1108-1121, 2014.

FILBY, N.E.; STOCKIN, K.A.; SCARPACI, C. Social science as a vehicle to improve dolphin-swim tour operation compliance? Marine Policy, v. 51, p. 40-47, 2015.

FINKLER, W.; HIGHAM, J. The human dimensions of whale watching: An analysis based on viewing platforms. Human Dimensions of Wildlife, v. 9, n. 2, p. 103-117, 2004. 
FREITAS, D.C.; SILVA, P.C.M.; LUNARDI, V.O.; SANTOS, J.E.A.; LUNARDI, D.G. Uso e Ocupação do Solo na Reserva Faunística Costeira de Tibau do Sul (REFAUTS), Rio Grande do Norte, Brasil (1984-2015). Revista Brasileira de Geografia Física, v. 9, n. 6, p. 1880-1887, 2016.

FUNDAÇÃO FLORESTAL. Portaria Normativa no 045/2007. Estabelece normas e procedimentos para o credenciamento de embarcações de turismo comercial e a limitação da navegação às embarcações que navegam no entorno do Parque Estadual Ilha do Cardoso, a fim de preservar as populações de boto-cinza, ordenar a visitação pública e prevenir contra a poluição do meio ambiente marinho. Disponível em: http://arquivos.ambiente.sp.gov.br/fundacaoflorestal/2014/01/PORTARIA-F.F.N\%C2\%AA045-2007.pdf. Acesso em: 08 mar. 2018.

GARCÍA-CEGARRA, A.M.; PACHECO, A.S. Whale-watching trips in Peru lead to increases in tourist knowledge, pro-conservation intentions and tourist concern for the impacts of whale-watching on humpback whales. Aquatic Conservation: Marine and Freshwater Ecosystems, v. 27, n. 5, p. 1011-1020, 2017.

GUERRA, M.; DAWSON, S.M. Boat-based tourism and bottlenose dolphins in Doubtful Sound, New Zealand: The role of management in decreasing dolphinboat interactions. Tourism Management, v. 57, p. 3-9, 2016.

HOWES, L.; SCARPACI, C.; PARSONS, E.C.M. Ineffectiveness of a marine sanctuary zone to protect burrunan dolphins (Tursiops australis sp. nov.) from commercial tourism in Port Phillip Bay, Australia. Journal of Ecotourism, v. 11, n. 3, p. 188-201, 2012.

HUNT, C.A.; DURHAM, W.H.; DRISCOLL, L.; HONEY, M. Can ecotourism deliver real economic, social, and environmental benefits? A study of the Osa Peninsula, Costa Rica. Journal of Sustainable Tourism, v. 23, n. 3, p. 339-357, 2015.

IMRAN, S.; ALAM, K.; BEAUMONT, N. Environmental orientations and environmental behaviour: Perceptions of protected area tourism stakeholders. Tourism Management, v. 40, p. 290-299, 2014.

INSTITUTO BRASILEIRO DO MEIO AMBIENTE E DOS RECURSOS NATURAIS RENOVÁVEIS - IBAMA. Portaria № 117, de 26 de dezembro de 1996. Estabelece a regulamentação da observação de cetáceos no território nacional. Diário Oficial da União, Poder Executivo, Brasília, DF, 26 dez. 1996. Seção 1, p. 028786.

INSTITUTO BRASILEIRO DO MEIO AMBIENTE E DOS RECURSOS NATURAIS RENOVÁVEIS - IBAMA. Portaria ํㅜㄴ 24, de 13 de fevereiro de 2002. Estabelece a regulamentação da observação de cetáceos no território nacional. Diário Oficial da União, Poder Executivo, Brasília, DF, 13 fev. 2002. Seção 1, p. 67.

INSTITUTO BRASILEIRO DO MEIO AMBIENTE E DOS RECURSOS NATURAIS RENOVÁVEIS - IBAMA. Portaria no 5-N, de 25 de janeiro de 1995. Estabelece normas para proteger a reprodução, descanso e as crias dos golfinhos (Stenella longirostris), no Arquipélago de Fernando de Noronha. Disponível em: http://www.icmbio.gov.br/cepsul/images/stories/legislacao/

Portaria/1995/p ibama 051995 regulamentaprotecaogolfinhos fernandonoronh a.pdf. Acesso em: 27 fev. 2018. 
INSTITUTO CHICO MENDES DE CONSERVAÇÃO DA BIODIVERSIDADE ICMBIO. Instrução Normativa ICMBio nํ2, de 03 de maio de 2016. Dispõe sobre normas e procedimentos administrativos para autorização de uso para a prestação do serviço de condução de visitantes em unidades de conservação federais, conforme as informações contidas no processo $n^{\circ} 02070.001887 / 2012$ 05. Diário Oficial da União, Poder Executivo, Brasília, DF, 04 maio. 2016. Seção 1, p. 115.

INSTITUTO NACIONAL DE METEOROLOGIA - INMET. BDMEP (Banco de Dados Meteorológicos para Ensino e Pesquisa). Disponível em: http://www.inmet.gov.br/portal/index.php?r=bdmep/bdmep. Acesso em: 28 jul. 2017.

JOHNSON, G.; MCLNNIS, C. Whale-watching: An effective education programme is no fluke. In: HIGHAM, J.; BEDJER, L.; WILLIAMS, R. (Org.). Whale-watching: Sustainable tourism and ecological management, Cambridge: Cambridge University Press., 2014, p. 128-145.

KESSLER, M.; HARCOURT, R. Aligning tourist, industry and government expectations: A case study from the swim with whales industry in Tonga. Marine Policy, v. 34, n. 6, p. 1350-1356, 2010.

KESSLER, M.; HARCOURT, R. Whale watching regulation compliance trends and the implications for management off Sydney, Australia. Marine Policy, v. 42, p. 14-19, 2013.

MARTINS, D.T.L.; ROSSI-SANTOS, M.R.; SILVA, F.J.L. Effects of anthropogenic noise on the acoustic behaviour of Sotalia guianensis (van Bénéden, 1864) in Pipa, North-eastern Brazil. Journal of the Marine Biological Association of the United Kingdom, v. 98, n. 2, p. 215-222, 2018.

LÜCK, M. Education on marine mammal tours-But what do tourists want to learn? Ocean \& Coastal Management, v. 103, p. 25-33, 2015.

LUNARDI, D.G.; FERREIRA, R.G. Fission-fusion dynamics of Guiana dolphin (Sotalia guianensis) groups at Pipa Bay, Rio Grande do Norte, Brazil. Marine Mammal Science, v. 30, n. 4, p. 1401-1416, 2014.

LUNARDI, D.G.; SANTOS, J.E.A.; NASCIMENTO, L.L.S.; FREITAS, D.C.; LUNARDI, V.O. Avaliação do turismo de observação de botos-cinza na Reserva Faunística Costeira de Tibau do Sul (Refauts), Rio Grande do Norte, Brasil. Sustentabilidade em Debate, v. 8, n. 1, p. 40-53, 2017.

MINISTÉRIO DO MEIO AMBIENTE - MMA. Espécies Ameaçadas - Lista 2014. 2014. Disponível em: http://www.icmbio.gov.br/ portal/faunabrasileira/lista-deespecies. Acesso em: 22 set. 2017.

MORAES, L.C.A. Políticas Públicas: ecoturismo x preservação dos recursos naturais. Revista Brasileira de Ecoturismo, v. 8, n. 4, p. 444-461, 2015.

ORAMS, M.B. Tourists getting close to whales, is it what whale-watching is all about? Tourism Management, v. 21, n. 6, p. 561-569, 2000.

ORAMS, M.B. Towards a more desirable form of ecotourism. Tourism Management, v. 16, n. 1, p. 3-8, 1995.

PARSONS, E.C.M. The negative impacts of whale-watching. Journal of Marine Biology, p. 1-9, 2012. 
PARSONS, E.C.M.; WOODS-BALLARD, A. Acceptance of voluntary whalewatching codes of conduct in West Scotland: The effectiveness of governmental versus industry-led guidelines. Current Issues in Tourism, v. 6, n. 2, p. 172-182, 2003.

PEREIRA, A.I.A.; SILVA, F.J.L.; SILVA JR, J.M. Influência dos cursos de capacitação do projeto golfinho rotador na atuação profissional dos condutores de ecoturismo em Fernando de Noronha (PE): uma contribuição a sustentabilidade turística local. Revista Brasileira de Ecoturismo, v. 8, n. 1, p. 31-58, 2015.

PONNAMPALAM, L.S. Dolphin watching in Muscat, sultanate of Oman: Tourist perceptions and actual current practice. Tourism in Marine Environments, v. 7, n. 2, p. 81-93, 2011.

RIBAS, L.C.C.; HICKENBICK, C. O papel de condutores ambientais locais e de cursos de capacitação no ecodesenvolvimento turístico e as expectativas sociais no sul do Brasil. Revista Turismo em Análise, v. 23, n. 1, p. 143-165, 2012.

RYAN, C; BOLIN, V.; SHIRRA, L.; GARRARD, P.; PUTSEY, J.; VINES, J.; HARTNY-MILLS, L. The development and value of whale-watch tourism in the west of Scotland. Tourism in Marine Environments, v. 13, n. 1, p. 17-24, 2018.

SANTOS-JR, E.; PANSARD, K.C.; YAMAMOTO, M.E.; CHELLAPPA, S. Behavior of estuarine dolphin, Sotalia guianensis (Van Bénédén) (Cetacea, Delphinidae) in the presence of tourist boats in Pipa Beach, Rio Grande do Norte, Brazil. Revista Brasileira de Zoologia, v. 23, n. 3, p. 661-666, 2006.

SCHLINDWEIN, M.N.; AKAKI, A.T.; LAGANARO, N.M. Atividades de observação do comportamento de Sotalia guianensis como subsídio para o turismo científico no Parque Estadual Ilha do Cardoso-Cananéia (SP). Revista Brasileira de Ecoturismo, v. 4, n. 2, p. 196-207, 2011.

SECCHI, E. 2012. Sotalia guianensis. The IUCN Red List of Threatened Species 2012: Disponível em: http://dx.doi.org/10.2305/IUCN.UK.2012.RLTS.T181359A17583662.en Acesso em: 12 mar. 2018.

SILVA, L.A.F.; MORITZ, T.; CAMARA, M.G.; SIGNORETTI, A. Turismo de observação de cetáceos no litoral sul do Rio Grande do Norte, Brasil. Revista Turismo \& Desenvolvimento, v. 21, n. 4, p. 423-436, 2014.

SILVA, V.M.F.; FETTUCCIA, D.; RODRIGUES, E.S.; EDWARD, H.; MORENO, I.B.; MOURA, J.F.; WEDEKIN, L.L.; BAZZALO, M.; EMIN-LIMA, N.R.; CARMOS, N.A.S.; SICILIANO, S.; UTRERAS, V. Report of the working group on distribution, habitat characteristics and preferences, and group size. Latin American Journal of Aquatic Mammals, v. 8, n. 1-2, p. 31-38, 2010.

SITAR, A.; MAY-COLLADO, L.J.; WRIGHT, A.J.; PETERS-BURTON, E.; ROCKWOOD, L.; PARSONS, E.C.M. Boat operators in Bocas del Toro, Panama display low levels of compliance with national whale-watching regulations. Marine Policy, v. 68, p. 221-228, 2016.

SITAR, A.; MAY-COLLADO, L.J.; WRIGHT, A.J.; PETERS-BURTON, E.; ROCKWOOD, L.; PARSONS, E.C.M. Tourists' perspectives on dolphin watching in Bocas Del Toro, Panama. Tourism in Marine Environments, v. 12, n. 2, p. 79-94, 2017. 
TIBAU DO SUL-RN. Decreto no 14, de 17 de fevereiro de 2006. Dispõe sobre a criação da Reserva Faunística Costeira de Tibau do Sul - REFAUTS, e dá outras providências. Diário Oficial da Prefeitura de Tibau do Sul, Poder Executivo, Tibau do Sul, RN, 17 fev. 2006.

TIBAU DO SUL-RN. Lei № 349, de 28 de dezembro de 2007. Dispõe sobre o transporte marítimo de visitação turística no âmbito da Reserva Faunística Costeira de Tibau do Sul - REFAUTS, e dá outras providências. Diário Oficial da Prefeitura de Tibau do Sul, Poder Executivo, Tibau do Sul, RN, 28 dez. 2007.

TISCHER, M.C.; SILVA-JR, J.M.; SILVA, F.J. de L. Interactions of spinnerdolphins (Stenella longirostris) (Cetacea, Delphinidae) with boats at the Archipelago of Fernando de Noronha, Brazil. Pan-American Journal of Aquatic Sciences, v. 8, n. 4, p. 339-346, 2013.

TOLEDO, G.A.C.; FURNI, F.R.G.; FERREIRA, P.H.P.; GARCIA, F.C.P.; FERREIRA, R.G.; SOUSA-LIMA, R.S. Epimeletic behavior of Guiana Dolphins (Sotalia guianensis) towards a calf supposedly killed by a motorboat in Brazil. Aquatic Mammals, v. 43, n. 6, p. 614-617, 2017.

TOSI, C.H.; FERREIRA, R.G. Behavior of estuarine dolphin, Sotalia guianensis (Cetacea, Delphinidae), in controlled boat traffic situation at southern coast of Rio Grande do Norte, Brazil. Biodiversity \& Conservation, v. 18, n. 1, p. 67-78, 2008.

VALLE, A.L.; MELO, F.C.C. Alterações comportamentais do golfinho Sotalia guianensis (Gervais, 1953) provocadas por embarcações. Biotemas, v. 19, n. 1, p. 75-80, 2006.

WALKER, K.; WEILER, B. A new model for guide training and transformative outcomes: A case study in sustainable marine-wildlife ecotourism. Journal of Ecotourism, v. 16, n. 3, p. 269-290, 2016.

WEARING, S.L.; CUNNINGHAM, P.A.; SCHWEINSBERG, S.; JOBBERNS, C. Whale watching as ecotourism: How sustainable is it? Cosmopolitan Civil Societies: An Interdisciplinary Journal, v. 6, n. 1, p. 38-55, 2014.

WHITT, A.D.; READ, A.J. Assessing compliance to guidelines by dolphinwatching operators in Clearwater, Florida, USA. Tourism in Marine Environments, v. 3, n. 2, p. 117-130, 2006.

WOOD, M.E. Ecotourism: principles, practices \& policies for sustainability. Paris: United Nations Environment Programme (UNEP), 2002.

WOODS-BALLARD, A.J.; PARSONS, E.C.M.; HUGHES, A.J.; VELANDER, K.A.; LADLE, R.J.; WARBURTON, C.A. The sustainability of whale-watching in Scotland. Journal of Sustainable Tourism, v. 11, n. 1, p. 40-55, 2003.

ZAPETIS, M.E.; SAMUELSON, M.M.; ACOSTA, N.B.; KUCZAJ, S.A. Evaluation of a developing ecotourism industry: Whale watching in the Gulf of Tribugá, Colombia. International Journal of Comparative Psychology, v. 30, 2017.

ZEPPEL, H.; MULOIN, S. Green messengers or nature's spectacle: Understanding visitor experiences of wild cetacean tours. In: HIGHAM, J.; BEDJER, L.; WILLIAMS, R. (Org.). Whale-watching: Sustainable tourism and ecological management, Cambridge: Cambridge University Press., 2014, p. 110-127. 


\section{Agradecimentos}

O presente trabalho foi realizado com apoio da Coordenação de Aperfeiçoamento de Pessoal de Nível Superior - Brasil (CAPES), através de concessão de bolsa de mestrado às autoras Josivânia Emanuelly Azevedo dos Santos, Diana Carvalho de Freitas e Maria Mayara dos Santos Silva e de recursos do Programa de Apoio à Pós-Graduação (PROAP).

Josivânia Emanuelly Azevedo dos Santos: Universidade Federal Rural do Semi-Árido, Mossoró, RN, Brasil.

E-mail: emanuelly.josivania@gmail.com

Link para o currículo Lattes: http://lattes.cnpq.br/0238894157731037

Vitor de Oliveira Lunardi: Universidade Federal Rural do Semi-Árido, Mossoró, RN, Brasil.

E-mail: lunardi.vitor@ufersa.edu.br

Link para o currículo Lattes: http://lattes.cnpq.br/2502162313135026

Diana Carvalho de Freitas: Universidade Federal Rural do Semi-Árido, Mossoró, RN, Brasil.

E-mail: dcrvfreitas@gmail.com

Link para o currículo Lattes: http://lattes.cnpq.br/0194403654132765

Maria Mayara dos Santos Silva: Universidade Federal Rural do Semi-Árido, Mossoró, RN, Brasil.

E-mail: mayarasantos.eco@gmail.com

Link para o currículo Lattes: http://lattes.cnpq.br/3056338424243063

Diana Gonçalves Lunardi: Universidade Federal Rural do Semi-Árido, Mossoró, RN, Brasil.

E-mail: lunardi.diana@ufersa.edu.br

Link para o currículo Lattes: http://lattes.cnpq.br/3614629176970801

Data de submissão: 11 de abril de 2018

Data de recebimento de correções: 03 de agosto de 2018

Data do aceite: 03 de agosto de 2018

Avaliado anonimamente 